\title{
N-acetyltransferase 2: Slow, intermediate or fast? A booming question of the molecular epidemiology in cancer research
}

\author{
Giuliano Di Pietro $^{1 *}$, Sandra Rocha Gadelha ${ }^{2}$, Sandra Mara Bispo Sousa ${ }^{3}$, \\ Paulo Roberto Santana de Melo ${ }^{2}$, Fabricio Rios Santos ${ }^{4}$ \\ ${ }^{1}$ Federal University of Sergipe, Lagarto, Brazil \\ ${ }^{2}$ State University of Santa Cruz, Ilhéus, Brazil \\ ${ }^{3}$ State University of Southwest Bahia, Vitória da Conquista, Brazil \\ ${ }^{4}$ Federal University of Mato Grosso, Cuiaba, Brazil \\ Email: *dipietrobr@yahoo.com.br
}

Received 9 August 2012; revised 7 September 2012; accepted 16 September 2012

\begin{abstract}
Throughout history, humanity has referred to reactions occurring with food, plants and, recently, medicines or drugs. The increase in pulmonary tuberculosis cases and the availability of treatment showed that genetic human differences can interfere in the capacity to metabolize drugs. There are remarkable genetic polymorphisms of $\mathrm{N}$-acetyltransferase 2 (NAT2) activity that have been associated with different levels of susceptibility to developing many kinds of cancers. This review considers the field as an open window for the application of molecular epidemiology tools that led to the development of pharmacogenomics. We cover historical data and the most recent knowledge about $N A T 2$ genetic polymorphisms and its distribution in different populations, which is an important concept being incorporated in epidemiological studies of cancer risk. We present up to date information about these studies, including meta-analysis based on the NAT2 distribution in different types of cancer. A critical broad at advances in NAT2 research, highlighting recent studies related to $N A T 2$ alleles in cancer susceptibility. Although there are multifactorial aspects involved in cancer risk, the variability in $N A T 2$ allelic frequency can be related to carcinogenesis through alterations in the metabolic rate after exposure to carcinogens.
\end{abstract}

Keywords: Cancer; Ethnicity; Genetic Variants; $\mathrm{N}$-Acetyltransferase 2

\section{INTRODUCTION}

$\mathrm{N}$-acetyltransferase $2(N A T 2)$ is a crucial enzyme in

"Corresponding author. clinical pharmacology. This enzyme and its gene play an important role in the metabolism of many drugs and xenobiotics (chemicals present in cigarette smoke, certain diets and in the environment) [1]. Historically, NAT2 has been associated with a different response to tuberculosis therapy $[2,3]$. The acetylators phenotypes profiles related to $N A T 2$ were described about 60 years ago, and it was one of the earliest hereditary traits identified that altered the drug metabolism [4]. In fact, it has been observed that exposure to a particular drug or substance does not result in the same degree of risk for all individuals. Differences between individuals, for example, in the processing of changes and damage to DNA are fundamental.

One of the most important sources of variation is precisely the xenobiotic metabolism system, found mainly in the liver but also present in almost all tissues. The "phase I" metabolizing enzymes are mainly cytochrome P450 (CYP), whose main function is to convert to reactive electrophilic metabolites by oxidation. The ironic point is that many chemicals become carcinogenic only when they are converted to a reactive form by CYPs. The next stage of detoxification is often the conjugation of reactive compounds and endogenous molecules by "phase 2" metabolizing enzymes, which may or may not convert them into inactive compounds before elimination. Aromatic and heterocyclic amines require metabolic activation to form electrophilic intermediates that may initiate carcinogenesis. In this case, NAT2 (NAT2, EC 2.3.1.5) is an important "starting point" as it is a crucial enzyme in the biotransformation of carcinogens. In fact, NAT2 enzymes are related to the metabolism of heterocyclic aromatic amines and they are particularly active in the liver, gastrointestinal tract and bladder, among other organs and tissues $[1,5,6]$. In the metabolic scheme for these drugs and carcinogens, NAT2 catalyzes not only 
$\mathrm{N}$-acetylation, but following $\mathrm{N}$-hydroxylation also catalyzes subsequent $\mathrm{O}$-acetylation and $\mathrm{N}, \mathrm{O}$-acetylation.

In fact, several studies have been published analyzing different genes that encode proteins involved in activation (Phase I) and/or detoxification (phase II) of chemical carcinogens such as those present in tobacco, and their influence in the development of lung and aerodigestive cancer [7]. Besides, it has been verified that the genetic profile of an individual metabolic allele has a role in determining the rate in which carcinogens are eliminated and therefore the extent and time of carcinogen exposure $[6,8]$. Individuals who have inherited alleles that result in greater carcinogen effect should have a higher risk of developing cancer when compared to those who have inherited the alleles associated with lower risk $[1,9]$.

In view of the number of published reports on NAT2, xenobiotic metabolism and cancer, we have conducted this review to summarize the scientific advances of recent years using different sources such as the Medical Literature Analysis and Retrieval System Online (MEDLINE), Elsevier (ScienceDirect), EBSCOhost ${ }^{\circledR}$ (EBSCO) and Scientific Electronic Library Online (SciELO). We also evaluated the approaches using ethnicity, and genetic polymorphisms in this booming field of pharmacogenetics. Publication time was not the main consideration.

\section{NAT2 NOMENCLATURE AND GENERAL MOLECULAR ASPECTS}

$N A T$ genes are found in prokaryotes and eukaryotes. In humans they are codified into two loci, as two polymorphic and functional genes: NAT1 and NAT2, and a third loci, comprising a pseudogene-NATP [10], located at chromosome 8p23.1 - p21.3 (NAT1) and 8p22 (NAT2). In other species three other loci may be found producing a functional enzyme, or only one 1 locus. The two isoenzymes NAT1 and NAT2, of 290 amino acids, present differences as tissue distribution, as well as to their substrates specificity profile and regulation. Both consist of a single open reading frame of 870 base pairs and present $81 \%$ of similarity in the amino acid sequence, while proteins differ in only 55 amino acids [11].

The location of the NAT gene was initially made by Blum et al. in 1990 [12], whereas the description was published in 1989 by Grant et al. [13], after the determination of the gene's location, finally the tissue distribution of the enzymes was performed in a few works. In 2000, Windmil et al. showed the presence of RNAm for the enzyme in the liver and in others extra hepatic tissues, especially bladder and intestinal tissues [14]. Its presence also in the lungs suggested that inhaled pollutants could be metabolized by these enzymes. Subsequently its presence was demonstrated in breast tissues without enzy- matic activity, indicating that this could be the result of the low enzyme expression in these tissues [15].

$N A T$ activity variability is recognizably an important factor for the determination of the individual susceptibility to toxic effects of drugs and carcinogens. After sequencing and cloning of various NAT2 genes, it was suggested that phenotypic differences were due to Single Nucleotype Polymorphisms (SNP) [10], that are inherited combined as alleles or haplotypes, and are unequally distributed between ethnic groups [16,17]. The deduction of low, intermediate or fast acetylator is based on the co-expression of alleles or haplotypes determined as fast or slow. However, this determination is not so simple, with several phenotypes with different degrees of acetylation velocity, suggesting that the various SNPs and haplotypes must result in different effects.

Indeed, several mutations in the coding region, with different results, have been described in the NAT genes. These are detailed at (http://Louisville.edu/medschool/ pharmacology/consensus-human-arylamine-n-acetyltrans ferase-gene-nomenclature) [18]. In the human population more than 15 SNPs have been identified in the coding region of $N A T 1$ and more than 25 SNPs in NAT2, with different effects [17]. To NAT2, the most common SNPs are: $191 \mathrm{G}>\mathrm{A}, 282 \mathrm{C}>\mathrm{T}, 341 \mathrm{C}>\mathrm{T}, 481 \mathrm{C}>\mathrm{T}, 590 \mathrm{G}>$ A, $803 \mathrm{~A}>\mathrm{G}, 857 \mathrm{G}>\mathrm{A}$. However, to understand the true role of these polymorphisms more functional studies are necessary. Besides, many findings are not consistent or reproducible [17].

Due to $N A T$ 's functional role and its high genetic variability, many studies are being carried out to evaluate the association between alleles and some pathologies. However, due to the nomenclature difficulty, sometimes the interpretation and comparison of results was a complicated task [6]. In this way, it was difficult to accommodate the nomenclatures to other non-human species. In order to standardize and join the nomenclature, as well as to make the results comparable, in 1995 a consensus for NAT nomenclature was proposed and published, according to International Rules for Gene Nomenclature [19]. All proposed classification system is described in Vatsis et al [19]. Briefly, the root symbol was defined as: $N A T$, in uppercase Latin letters, and not $A T$ or $A C T$, to represent acetyltransferase. The loci encoding proteins with similar functions were distinguished by Arabic numerals, and the asterisk placed after the symbols (all in italic): $N A T 1^{*}$ and $N A T 2 *$. The alleles were represented by Arabic numerals and capitalized letters, immediately after the asterisk. $N A T 1 * 4$ and $N A T 2 * 4$ were defined as wild type to $N A T 1$ e $N A T 2$, respectively. The nomenclature to genotype and phenotype also were described and organized.

Even with the determination of consensus, new alleles continued to be identified, with confusion regarding the 
nomenclature, especially for human alleles. Thus, new updates were necessary and in 1998, in an event carried out in Kuranda, Queensland, Australia,

(http://www.pharm.uwa.edu.au/workshop/prog.html) the first Arylamine N-acetyltransferase Gene Nomenclature Committee was proposed [20]. Other workshops were also carried out every 3 years, after this first one, for the interchange between researchers of the field [21]. Subsequent events happened in Eynsham Hall, close to Oxford, UK, in 2001; Vancouver, Canada, in 2004 and Alexandropoulos, Greece, in 2007 [22,23]. The fifth workshop was recently carried out in Paris, France, in September 2010. Also in 2000, when the Arylamine $\mathrm{N}$-acetyltransferase Gene Nomenclature Committee was created, a website

(http://louisville.edu/medschool/pharmacology/consensushuman-arylamine-n-acetyltransferase-gene-nomenclature), was created where new identified alleles (independently of species) would still be classified according to the homology of the nucleotides' sequence, as per original rules and adequately included (this website is referenced by the website of Human Gene Nomenclature Committee for classification of $N A T$ ) [24].

During the workshop carried out in 2007, in Alexandropoulos, it was proposed that in 2008 a new website (http://www.mbg.duth.gr/non-humanNATnomenclature), linked to the first one, would be available to deal with the sequences in prokaryotes and eukaryotes - with the exception of humans and several selected non-human mammals. This proposal was due to the large amount of information generated in the $N A T$ field. It was also proposed that the alleles of all species, with the exception of rats and mice would still be written with capital letters. For these two last cases the first letter is capitalized and the following letters are in lower case (Nat). Furthermore, the nomenclature became species-specific, with the inclusion of information about the functional effects in human alleles [25].

\section{NAT2 ALLELES AND POPULATION DISTRIBUTION}

Complex diseases are the result of the interaction of genetic and environmental factors, and may be influenced by population ethnic diversity. Many recent studies have demonstrated the influence of the ethnic component in the genetic variation of NAT2 gene polymorphism [26]. The characterization of the alleles is important to determine if these variants differ between evaluated groups and if they confer a protection or susceptibility effect to diseases in the ethnical group under consideration.

NAT2 gene is one of the most well-known genetic polymorphisms in humans and displays a large genetic variability among different ethnic groups. From the variation of alleles/haplotypes presented by NAT2 gene it is possible to establish slow, intermediate and fast phenotypes, and genotypes that may be related to many diseases. Considering the ethnic variation in the distribution of mutant alleles in world populations (literature data, Table 1) [26,56] two major groups are clearly distinct, with higher incidence of the alleles $N A T 2 * 5$ and $N A T 2 * 7$. The frequencies of these two variants are very similar in Caucasians, Indians and Africans $(>0.100$ and $<0.150$ ). Populations of the Pacific and East Asia and native American populations from Panama also present higher homogeneity in the frequency of alleles $N A T 2 * 5$ and $N A T 2^{*} 7$, ranging from $<0.099$ to $>0.04$, respectively. Allele $N A T 2 * 6$ presents higher frequency in Caucasians and are defined as slow acetylators; in contrast, some Asians-Japanese, Koreans and Chinese-present intermediate frequencies of $N A T 2 * 6$ (Table 1). Allele $N A T 2 * 14$ appears to be characteristic of Sub-Sahara Africans and Afro-Americans (Table 1).

Table 1. NAT2 allele frequencies in worldwide populations.

\begin{tabular}{|c|c|c|c|c|c|c|c|c|c|c|}
\hline \multicolumn{2}{|c|}{ Etnic group/Country } & $N A T 2 * 4$ & $N A T 2 * 5$ & $N A T 2 * 6$ & $N A T 2 * 7$ & $N A T 2 * 12$ & $N A T 2 * 13$ & $N A T 2 * 14$ & Others & Ref. \\
\hline \multicolumn{11}{|l|}{ Caucasianos } \\
\hline Hispanic US & 65 & 0.390 & 0.320 & 0.190 & 0.100 & & & & & [29] \\
\hline Saami & 20 & 0.350 & 0.350 & 0.150 & 0.150 & & & & & [30] \\
\hline Hispanics & 245 & 0.314 & 0.363 & 0.222 & 0.076 & 0.014 & 0.010 & & & [28] \\
\hline Poland & 316 & 0.260 & 0.437 & 0.288 & 0.015 & & & & & [31] \\
\hline Danish & 242 & 0.254 & 0.473 & 0.250 & 0.023 & & & & & [32] \\
\hline French & 20 & 0.250 & 0.300 & 0.450 & & & & & & [30] \\
\hline Americans & 372 & 0.250 & 0.450 & 0.280 & 0.020 & & & & & [33] \\
\hline North Carolina & 523 & 0.240 & 0.470 & 0.270 & 0.020 & & & & & [34] \\
\hline Danish & 1216 & 0.230 & 0.472 & 0.275 & 0.023 & & & & & [35] \\
\hline German & 844 & 0.227 & 0.465 & 0.278 & 0.013 & & 0.015 & 0.001 & & [36] \\
\hline Non-Hispanics & 490 & 0.224 & 0.441 & 0.308 & 0.024 & 0.010 & 0.001 & & & [28] \\
\hline Americans & 266 & 0.220 & 0.470 & 0.280 & 0.003 & & & & & [29] \\
\hline Hispanic & 504 & 0.216 & 0.442 & 0.256 & 0.012 & 0.037 & 0.019 & 0.015 & & [37] \\
\hline
\end{tabular}


Continued

\begin{tabular}{|c|c|c|c|c|c|c|c|c|c|c|}
\hline Portuguese & 128 & 0.212 & 0.433 & 0.328 & 0.027 & & & & & {$[38]$} \\
\hline United Kingdom & 63 & 0.210 & 0.470 & 0.310 & 0.020 & & & & & [39] \\
\hline Scottish & 96 & 0.203 & 0.490 & 0.271 & 0.036 & & & & & [40] \\
\hline Swedish & 70 & 0.194 & 0.507 & 0.278 & 0.021 & & & & & [40] \\
\hline European & 62 & 0.194 & 0.435 & 0.339 & 0.032 & & & & & [41] \\
\hline Sardinians & 12 & 0.167 & 0.583 & 0.250 & & & & & & [30] \\
\hline Ashkenazi & 20 & 0.100 & 0.400 & 0.500 & & & & & & [30] \\
\hline $\begin{array}{c}\text { Total n/range } \\
\text { Koreans }\end{array}$ & 5574 & $0.100-0.390$ & $0.300-0.583$ & $0.150-0.500$ & $0.003-0.150$ & $0.010-0.037$ & $0.001-0.019$ & $0.001-0.015$ & & \\
\hline Koreans & 85 & 0.692 & 0.018 & 0.180 & 0.110 & & & & & [29] \\
\hline Japanese & 2000 & 0.657 & 0.016 & 0.201 & 0.115 & 0.008 & 0.001 & & 0.004 & [42] \\
\hline Polynesians & 79 & 0.641 & 0.019 & 0.230 & 0.110 & & & & & [29] \\
\hline Chinese & 25 & 0.600 & 0.040 & 0.340 & 0.020 & & & & & [29] \\
\hline Chinese & 154 & 0.571 & 0.036 & 0.247 & 0.146 & & & & & [43] \\
\hline Taiwanese & 441 & 0.523 & 0.060 & 0.305 & 0.112 & & & & & [44] \\
\hline Japanese & 100 & 0.515 & 0.025 & 0.310 & 0.150 & & & & & [29] \\
\hline Hong Kong & 96 & 0.510 & 0.010 & 0.281 & 0.114 & 0.073 & 0.011 & & & [45] \\
\hline Pacific Rim & 70 & 0.473 & 0.057 & 0.310 & 0.160 & & & & & [29] \\
\hline Filipino & 48 & 0.417 & 0.083 & 0.313 & 0.188 & & & & & [41] \\
\hline Taiwanese & 100 & 0.395 & 0.065 & 0.360 & 0.180 & & & & & [29] \\
\hline Gujarati & 235 & 0.381 & 0.038 & 0.326 & 0.205 & & 0.051 & & & [46] \\
\hline Thai & 20 & 0.300 & 0.300 & 0.350 & 0.050 & & & & & [30] \\
\hline Koreans & 28 & 0.286 & 0.143 & 0.429 & 0.107 & & 0.036 & & & [30] \\
\hline Total n/range & 3481 & $0.286-0.692$ & $0.010-0.300$ & $0180-0.429$ & $0.020-0.205$ & $0.008-0.073$ & $0.001-0.051$ & & 0.004 & \\
\hline \multicolumn{11}{|c|}{ Indians and Arabs } \\
\hline Tunisian & 125 & 0.516 & 0.436 & 0.020 & 0.028 & & & & & [47] \\
\hline Iranians & 88 & 0.430 & 0.320 & 0.190 & 0.060 & & & & & [48] \\
\hline Central Asian & 138 & 0.380 & 0.210 & 0.300 & 0.110 & 0.002 & & & & [49] \\
\hline Iranians & 229 & 0.299 & 0.314 & 0.380 & 0.007 & & & & & [50] \\
\hline Indians & 61 & 0.257 & 0.330 & 0.380 & 0.033 & & & & & [29] \\
\hline \multicolumn{2}{|c|}{$\begin{array}{l}\text { Etnic group/Country n } \\
\text { Indians and Arabs }\end{array}$} & $N A T 2 * 4$ & $N A T 2 * 5$ & $N A T 2 * 6$ & $N A T 2 * 7$ & $N A T 2 * 12$ & $N A T 2 * 13$ & $N A T 2 * 14$ & Others & Ref. \\
\hline Turkish & 303 & 0.231 & 0.417 & 0.305 & 0.045 & 0.002 & & & & [51] \\
\hline Egyptians & 199 & 0.215 & 0.497 & 0.260 & 0.028 & & & & & [52] \\
\hline Emiratis & 106 & 0.180 & 0.540 & 0.210 & 0.040 & & & & & [53] \\
\hline $\begin{array}{c}\text { Total n/range } \\
\text { Africans }\end{array}$ & 1249 & $0.180-0.516$ & $0.210-0.540$ & $0.020-0.380$ & $0.007-0.110$ & 0.002 & & & & \\
\hline Afro-Americans & 214 & 0.430 & 0.295 & 0.230 & 0.045 & & & & & [29] \\
\hline North Carolina & 307 & 0.380 & 0.270 & 0.260 & 0.030 & & & 0.050 & & [34] \\
\hline Afro-Americans & 128 & 0.360 & 0.300 & 0.220 & 0.020 & & & 0.090 & & [33] \\
\hline Ancestry African & 48 & 0.146 & 0.271 & 0.250 & & 0.229 & 0.104 & & & [41] \\
\hline Bantu & 20 & 0.150 & 0.550 & 0.100 & & 0.100 & 0.050 & 0.050 & & [30] \\
\hline Bakola & 20 & 0.100 & 0.100 & 0.150 & & 0.500 & 0.150 & & & [30] \\
\hline Sub-Sahara Afric. & 117 & 0.094 & 0.359 & 0.274 & 0.022 & 0.119 & 0.064 & 0.068 & & [54] \\
\hline Madenka & 97 & 0.093 & 0.360 & 0.170 & 0.067 & 0.155 & 0.052 & 0.103 & & [55] \\
\hline $\begin{array}{l}\text { Total } \mathbf{n} / \text { range } \\
\text { Ngawbe }\end{array}$ & 951 & $0.093-0.430$ & $0.100-0.550$ & 0.100 - 0.274 & $0.020-0.067$ & $0.100-0.500$ & $0.050-0.150$ & $0.050-0.103$ & & \\
\hline Embera & 105 & 0.724 & 0.024 & & 0.233 & & 0.019 & & & [56] \\
\hline Native Americans & 136 & 0.610 & 0.099 & 0.037 & 0.228 & & 0.026 & & & [56] \\
\hline Siberia & 384 & 0.378 & 0.253 & 0.047 & 0.230 & 0.01 & 0.078 & & 0.003 & [57] \\
\hline Ngawbe & 72 & 0.319 & 0.209 & 0.236 & 0.153 & & 0.042 & & 0.042 & [57] \\
\hline Total n/range & 697 & $0.319-0.724$ & $0.024-0.253$ & $0.037-0.236$ & $0.153-0.233$ & 0.01 & $0.019-0.078$ & & $0.003-0.042$ & \\
\hline Brazilians & 404 & 0.200 & 0.380 & 0.267 & 0.040 & 0.040 & 0.030 & 0.040 & 0.040 & [58] \\
\hline
\end{tabular}


Emphasis must be given to the high frequencies of alleles $N A T 2 * 7$ and $N A T 2 * 12$ among Native Americans and Sub-Sahara Africans, respectively; the first allele is defined as substrate-dependent slow acetylator and the second as fast acetylator

(http://louisville.edu/medschool/pharmacology/consensu s-human-arylamine-n-acetyl

transferase-gene-nomencla-ture) [18]. Populations of the East Asia present higher proportion of allele $N A T 2 * 4-$ among Koreans the frequency reaches almost 70\% [27] whereas populations of the African sub-Sahara present the lowest frequencies of allele $N A T 2 * 12$, which is also defined as fast acetylator. According to Sabbagh et al. (2008) derived haplotypes related to fast acetylator phenotype (cluster $N A T 2 * 12$ ), are found mainly in Africa and are particularly frequent in Baka and among Bakola pygmies that display a proportion of fast acetylators similar to East Asians (83\% and 90\%, respectively) [53].

Besides of being useful in association studies in casecontrol samples with complex diseases, these polymorphisms may be used for population studies which are still not common. The Brazilian population, resulting from five centuries of miscegenation among Amerindians, Africans and Europeans (mainly Portuguese), presents a particular picture of the world distribution as regards the variation of alleles frequencies $(N A T 2 * 5, N A T 2 * 7$, $N A T^{*} 12$ and $\left.N A T 2 * 14\right)$ of gene NAT2 [56,57]. This indicates that this polymorphism may also be used to characterize the intra- and inter-ethnic genetic diversity [58] and ancestry of recent populations. Indeed, as they are not selectively neutral (coding regions) they may be useful in evolution models to test the natural selection probably driven by lifestyle and dietary habits of the population $[28,47,53]$.

Currently there are some limiting factors that restrict the use of this polymorphism. The first one concerns the obtaining method. In the future, the PCR/RFLP technique must be complemented with the sequencing, which will lead to a substantial increase of the number of variants in world populations. The second is the functional analysis which should be implemented to define the acetylation pattern of new variants.

\section{NAT2 POLYMORPHISMS AND CANCER SUSCEPTIBILITY}

The evaluation of genetic polymorphisms of xenobiotic metabolizing enzymes is an important tool in the cancer susceptibility study. In this context, some alleles or genotypes have been related with a higher or lower predisposition to the development of this morbidity. As previously stated, due to the biological role of NAT2, capacity of reacting with environmental carcinogens such as polycyclic aromatic hydrocarbons (PAHs), aromatic amines (AAs), heterocyclic amines (HAs) and nitrosamines (NAs), many studies have investigated the relation between different genetic polymorphisms in NAT2 and cancer. The genetic variation in the expression of this enzyme in different individuals has also been classified into several phenotypes, i.e., slow, intermediate or fast acetylation, which may be relevant in the determination of susceptibility to diseases.

Important studies have been done in the determination in the formation level of DNA adducts, that may be used as a genotoxicity biomarker. The study conducted by Turesky et al., (2009), for example, shows the influence of Nat 2 genetic polymorphisms in the appearance of adduct 3',5'-diphosphate- $N$-(2'-deoxyguanosin-8-yl)-A $\alpha \mathrm{C}$ (3',5'-pdGp-C8-A $\alpha \mathrm{C}$ ) formed in Chinese hamster ovary cells, after exposure to 2-amino-9H-pyrido[2,3-b]indole $(\mathrm{A} \alpha \mathrm{C})[59]$. This compound, formed in well-done meat and tobacco smoke, was the first genotoxic heterocyclic aromatic amine identified, showing the importance of the xenobiotic-gene interaction. In addition to the molecular/ genetic studies relating NAT2 and its antimutagenic role, it is worth noting the wide distribution of this enzyme in various human tissues, especially those in greater contact with xenobiotics [14].

Considering the aspects above, and in view of the practicality of collecting information on the association between the influence of genetic polymorphisms of metabolizing enzymes, as already done in reviews recently published [60], we will address here some types of cancer and possible associations with different phenotypes for NAT2. We will consider the following types: bladder, colorectal, head and neck, gastric, lung, breast and prostate cancer, since these are the most prevalent around the world and are also the most studied as to their relation with $N A T 2$.

\subsection{NAT2 Slow Phenotypes in Cancer Susceptibility}

Several case-control works published in the last years showed that phenotype NAT2 slow acetylator, alone or in combination with other polymorphic genes such as CYP, NAT1, GST and p53, among others, is more prevalent in individuals with different types of cancer, such as bladder [45,61-70], colorectal [71], head and neck [7,29, 72-78], gastric [79], lung [80-86], breast [87-92], and prostate cancer [93-95].

Overall, as expected by the biological activity of NAT2, most association studies find a positive correlation between slow acetylators and a higher genetic predisposition to the development of cancers. However, lifestyle seems to be extremely important for risk evaluation. Besides, the studies have used several methodologies and evaluated number and populations with dif- 
ferent backgrounds, making it difficult to compare data. In 2000, Hein et al., showed that the phonotypical analysis of different NAT2 genotypes is complex. Authors also discuss which $\mathrm{N}$-acetyltransferase activity reduction mechanisms are associated with the substitution of nucleotides present in several NAT2 alleles and that the ability to distinguish acetylation phenotypes is complex and depends on sensitivity and specificity of the phenotyping method [6]. Frazier et al. (2001) also suggest that there might be differences on slow acetylation phenotypes produced by different NAT2 genotypes, depending on the substrate [71]. Thus, further studies - especially functional ones - are needed to clarify these issues.

Besides of the positive association of NAT2 slow acetylators with different types of cancer, showed in various works, other works also verified the association between NAT2 slow acetylators with occupational and environmental exposure to carcinogens. Undoubtedly lung cancer (LC) is related to the direct contact with carcinogens present in cigarette smoke or environmental pollutants dispersed in the air, such as oral, head and neck cancer. NAT2 slow acetylator increased risk to lung cancer among Caucasian Swedes, Japanese and Indians $[82,84,85]$. mainly related to smoking habit in bladder cancer risk [61,62,66,68,69,96-105], or colorectal cancer related to smoking or higher meat intake [106,107-110], gastric cancer with high consumption of cigarettes [111], similarly, active smoking there is a slight increase of breast cancer risk among slow acetylators $[26,87,89,90$, 92,112-115], and to prostate cancer [93-95].

Moreover, the evaluation of the consumption of certain beverages such as coffee and alcohol, and eating food such as red meat, fruits and cruciferous, in association with NAT2 polymorphisms has been related to risk of development of BC. On the other hand, the regular intake of alcohol proved to be an additional risk factor for NAT2 slow acetylator individuals, as observed by $\mathrm{Lu}$ et al., $2005(\mathrm{OR}=18.04 ; 95 \% \mathrm{CI}=2.28-142.8)$ [116].

Some recent studies also show that the intake of products such as dark-green, yellow-orange and cruciferous vegetables, besides of citrus fruits/juices and tomato products function as protection factors against the development of BC [117-121], even for NAT2 slow acetylator individuals. During a study in Belgium, Kellen et al. (2006) observed that even smoking individuals that consumed a high amount of fruits presented lower risk in relation to smoking individuals that consumed a low amount of fruit $(\mathrm{OR}=2.15 ; 95 \% \mathrm{CI}=1.15-4.05$; and $\mathrm{OR}=4.23 ; 95 \% \mathrm{CI}=1.91-9.4$; respectively) $[122]$. Consistent with this hypothesis, slow/intermediate acetylators have a decreased capacity to detoxify dietary carcinogen to reactive metabolites that initiate DNA adducts and tumors, compared to rapid acetylators [111].

Based on the studies presented above we may con- clude, in a general but not unanimous way, that NAT2 slow acetylator individuals appear to present higher susceptibility to the development a different types of cancer, and that the exposure to carcinogenic substances increase this risk. On the other hand, the maintenance of healthy habits such as not smoking and consuming adequate amounts of fruits and cruciferous, can mitigate this effect.

\subsection{NAT2 Fast Phenotypes in Cancer Susceptibility}

The data are controversial as regards about NAT2 fast phenotypes and the development different kinds of cancer. Some authors observed relation between phenotypes and/or genotypes NAT2 of fast acetylation and a higher risk of CRC development [123-127]. We may highlight the meta-analysis conducted by Ye \& Parry (2002) that included 4,431 cases and 4,547 controls and observed that, for $N A T 2$ fast phenotype individuals, there was a risk of $1.51(95 \% \mathrm{CI}=1.07-2.12)$ for $\mathrm{CRC}$, while no relation was observed for NAT2 fast genotype individuals [128].

Some studies also suggest an increased CRC risk related to smoking and/or intake of red meat, associated to a higher frequency of NAT2 alleles of fast acetylation $[106,107,125,126,129-136]$. When the risk association measure included smoking exposure and intake of alcohol, fast or intermediate NAT2 acetylator individuals (separately analyzed or in combination with other polymorphic genes), are more prevailing among patients with head and neck cancer [137-141]. On the other hand, only one study observed the association with fast acetylator and LC [142] and other one found a risk association between PC with fast acetylators individous [141].

However, fast acetylators show higher risk LC among Caucasian Americans and Taiwanese [142,143]. It is worth highlighting the studies by Chang-Claude et al. (2002) and Conlon et al. (2010), who observed increase associations as regards acetylator NAT2 and breast cancer. While Chang-Claude observed an association between passive smoking and fast acetylators [113], an association was observed between fast acetylators and heavy smokers $(\mathrm{p}=0.005)$, thus showing the difficult in establishing a definitive association between NAT2 polymorphisms and breast cancer [92].

\subsection{NAT2 Phenotypes Not Show Association in Cancer Susceptibility}

However, studies with individuals of different ethnicities showed association of NAT2 slow, intermediate or fast acetylate, some studies also suggest an no significant difference between case and control in different types of cancer. Is an example, bladder cancer along [69], or in 
association with occupational and environmental exposure to carcinogens, mainly related to smoking habit [64,144,145-147]. In the same way CRC along [80,106, 148-158], related to smoking and/or intake of red meat $[123,125,129,130,149,158-161]$ or cigarette smoking and prostate cancer [162].

The case of head and neck cancer, some studies also suggest an no significant difference in NAT2 slow, intermediate or fast acetylate [7,29,72-78,163]. By analyzing a sample of American Caucasians, Chen, et al. (2001) also showed that the risk of developing oral cancer is important, regardless of being fast, intermediate or slow acetylator individual, if the amount of cigarettes ( $>20$ pack/years) or alcohol ( $>15$ drinks/week) intake is high [164]. Moreover, we may find some studies in which no association was observed with $N A T 2$ alleles and LC [7,81,83,165-167], and breast cancer, even when associated to smoking or red meat intake $[92,113,168$ 176], or prostate cancer [177-180].

As well as, it is worth highlighting that recently a meta-analysis performed by Zhong et al. (2010) was published; in this study 2391 GC cases and 3237 health controls were included and no association was observed between different NAT2 acetylators [181] like others works $[79,182,183]$.

\section{CONCLUSIONS}

The initial hypotheses on the reasons for cancer have postulated endogenous and/or exogenous pathways. While the first was intrinsically related to genetic influence, the other would depend on the environment, habits and behavior in a social and cultural context. However, new evidence has shown that the intersection between these two sources is much broader than the sum of their separate universes.

With relation to genetic influence, new approaches based on phases I and II enzyme genes involved in xenobiotics and endobiotics metabolism, such as $N A T$, is completely relevant. In fact, $N A T 2$ has been associated with cancer and this could be explained by its roles in the bioactivation and detoxification of heterocyclic aromatic amine carcinogens [7,184,185]. However, several studies have been unable to establish consistent evidence $[8,93,129,137,167,178]$. Besides that, the majority of the studies had used genotyping results to determine the phenotype (phenotypes slow, intermediate and fast are based on the determination of SNPs).

To observe the real relevance of NAT2 in cancer development, more structural and functional studies with different alleles are needed. In this field, recombinant expression systems have been used to characterize NAT2 variants. Human recombinant $N A T 2 * 5, N A T 2 * 6, N A T 2 *$ 7 , and $N A T 2 * 14$ clusters yield variable reductions in catalytic activity associated with slow acetylation phenotype, while human recombinant $N A T 2 * 12$, and $N A T 2 * 13$ clusters catalyze N-, O- and N,O-acetyltransferase activities at levels comparable to the rapid acetylator $N A T 2 * 4[186,187]$, indicating that these experiments must be useful tools to correlate genetic and functional aspects.

In addition, the molecular homology modeling techniques, including SNP locations and computational docking of substrates, have increased the understanding of the NAT2 protein structure-function relationship [22,188,189] The released crystal structure of human NAT2 made it possible to evaluate its structure-function without the particular limitation of the molecular homology modeling. Thus, increased pharmacogenomic understanding may enable huge advances. It will be possible, for example, to add genetic information related to susceptibility to disorders, such as different kinds of cancer, to the individualized drug treatment protocol. Finally, public health authorities need to understand the complexities of personalized medicine and be ready to apply this knowledge. In this context, the epidemiological, laboratorybased experiments and genetic haplotype map may represent complementary strands that link preventive and curative modern medicine.

Perhaps the small sample size of these studies published in the last years, as well as the small number of analyzed alleles, may be a main reason for this differences and divergence of the results. More studies are necessary, with higher ethnic diversity, so that the true role of NAT2 as regards susceptibility to cancer could be clarified. They also show that the development of cancers is multifactorial, depending of the genetic susceptibility, but also and principals of eating habits, smoking and alcohol intake or pollutions exposure.

\section{ACKNOWLEDGEMENTS}

The authors acknowledge the contributions of all investigators in the $\mathrm{N}$-acetyltransferase 2 field, particularly those who have worked with and generated data presented in this paper. The authors also acknowledge the relevant research grants from the National Council for Research (Conselho Nacional de Pesquisa-CNPq, Brazil).

\section{REFERENCES}

[1] Hein, D.W. (2002) Molecular genetics and function of NAT1 and NAT2: Role in aromatic amine metabolism and carcinogenesis. Mutation Research, 506, 65-77. doi:10.1016/S0027-5107(02)00153-7

[2] Hein, D.W. (2000) N-Acetyltransferase genetics and their role in predisposition to aromatic and heterocyclic amineinduced carcinogenesis. Toxicology Letters, 112, 349356. doi:10.1016/S0378-4274(99)00226-X

[3] Dupret, J.M., Dairou, J., Atmane, N., et al. (2004) Pharmacogenetics, regulation and structural properties of the 
drug metabolizing enzymes arylamine $\mathrm{N}$-acetyltransferases. Current Pharmacogenomics, 2, 333-338. doi:10.2174/1570160043377286

[4] Hughes, H., Biehl, J., Jones, A., et al. (1954) Metabolism of isoniazid in man as related to the occurrence of peripheral neuritis. American Review of Respiratory Disease, 70, 266-273.

[5] Estrada, L., Kanelakis, K.C., Levy, G.N., et al. (2000) Tissue- and gender-specific expression of N-acetyltransferase 2 (Nat $2 *$ ) during development of the outbred mouse strain CD-1. Drug Metabolism and Disposition, 28, 139146.

[6] Hein, D.W., McQueen, C.A., Grant, D.M., et al. (2000) Pharmacogenetics of the arylamine $\mathrm{N}$-acetyltransferases: a symposium in honor of Wendell W. Weber. Drug Metabolism and Disposition, 28, 1425-1432.

[7] McKay, J.D., Hashibe, M., Hung, R.J., et al. (2008) Sequence variants of NAT1 and NAT2 and other xenometabolic genes and risk of lung and aerodigestive tract cancers in Central Europe. Cancer Epidemiology, Biomarkers \& Prevention, 17, 141-147. doi:10.1158/1055-9965.EPI-07-0553

[8] Li, D., Jiao, L., Li, Y., et al. (2006) Polymorphisms of cytochrome P4501A2 and N-acetyltransferase genes, smoking, and risk of pancreatic cancer. Carcinogenesis, 27, 103111. doi:10.1093/carcin/bgi171

[9] Bartsch, H., Nair, U., Risch, A., et al. (2000) Genetic polymorphism of CYP genes, alone or in combination, as a risk modifier of tobacco-related cancers. Cancer Epidemiology, Biomarkers \& Prevention, 9, 3-28.

[10] Sim, E., Lack, N., Wang, C.J., et al. (2008) Arylamine Nacetyltransferases: Structural and functional implications of polymorphisms. Toxicology, 254, 170-183. doi:10.1016/j.tox.2008.08.022

[11] Grant, D.M. (2008) Structure of human arylamine N-acetyltransferases. Current Drug Metabolism, 9, 465-470. doi:10.2174/138920008784892029

[12] Blum, M., Grant, D.M., McBride, W., et al. (1990) Human arylamine $\mathrm{N}$-acetyltransferase genes: Isolation, chromosomal localization, and functional expression. DNA and Cell Biology, 9, 193-203. doi:10.1089/dna.1990.9.193

[13] Grant, D.M., Blum, M., Demierre, A., et al. (1989) Nucleotide sequence of an intronless gene for a human arylamine $\mathrm{N}$-acetyltransferase related to polymorphic drug acetylation. Nucleic Acids Research, 17, 3978. doi:10.1093/nar/17.10.3978

[14] Windmill, K.F., Gaedigk, A., Hall, P.M., et al. (2000) Localization of $\mathrm{N}$-acetyltransferases NAT1 and NAT2 in human tissues. The Journal of Toxicological Sciences, 54, 19-29. doi:10.1093/toxsci/54.1.19

[15] Williams, J.A. and Phillips, D.H. (2000) Mammary expression of xenobiotic metabolizing enzymes and their potential role in breast cancer. Cancer Research, 60, 4667- 4677.

[16] Vagena, E., Fakis, G. and Boukouvala, S. (2008) Arylamine $\mathrm{N}$-acetyltransferases in prokaryotic and eukaryotic genomes: A survey of public databases. Current Drug Metabolism, 9, 628-660.

doi: $10.2174 / 138920008785821729$
[17] Hein, D.W. (2009) N-acetyltransferase SNPs: Emerging concepts serve as a paradigm for understanding complexities of personalized medicine. Expert Opinion on Drug Metabolism \& Toxicology, 5, 353-366. doi: $10.1517 / 17425250902877698$

[18] Hein, D.W., Sim, E., Boukouvala, S., Grant, D.M. and Minchin, R.F. (2010) Arylamine N-acetyltransferase gene nomenclature committee.

http://louisville.edu/medschool/pharmacology/consensushuman-arylamine-n-acetyltransferase-gene-nomenclature

[19] Vatsis, K.P., Weber, W.W., Bell, D.A., et al. (1995) Nomenclature for N-Acetyltransferases. Pharmacogenetics, 5, 1-17. doi:10.1097/00008571-199502000-00001

[20] Ilett, K.F., Kadlubar, F.F. and Minchin, R.F. (1999) 1998 International meeting on the arylamine $\mathrm{N}$-acetyltransferases: Synopsis of the workshop on nomenclature, biochemistry, molecular biology, interspecies comparisons, and role in human disease risk. Drug Metabolism and Disposition, 27, 957-959. http://www.pharm.uwa.edu.au/workshop/prog.html

[21] Ilett, K.F., Kadlubar, F.F. and Minchin, R.F. (1999) International meeting on the arylamine N-acetyltransferases: Synopsis of the Workshop on nomenclature, biochemistry, molecular biology, interspecies comparisons, and role in human disease risk. Drug Metabolism and Disposition, 27, 957-959.

[22] Rodrigues-Lima, F., Blömeke, B., Sim, E., et al. (2002) NAT from bugs to brains. An overview of the 2nd International Workshop on the arylamine $\mathrm{N}$-acetyltransferases. The Pharmacogenomics Journal, 2, 152-155. doi:10.1038/sj.tpj.6500114

[23] Boukouvala, S., Westwood, I.M., Butcher, N.J., et al. (2008) Current trends in $\mathrm{N}$-acetyltransferase research arising from the 2007 International NAT workshop. Pharmacogenomics, 9, 765-771. doi:10.2217/14622416.9.6.765

[24] Boukouvala, S. and Fakis, G. (2008) The database of nonhuman $\mathrm{N}$-acetyltransferases (NATs). http://www.mbg.duth.gr/non-humanNATnomenclature

[25] Hein, D.W., Boukouvala, S., Grant, D.M., et al. (2008) Changes in consensus arylamine $\mathrm{N}$-acetyltransferase gene nomenclature. Pharmacogenet Genomics, 18, 367-368. doi:10.1097/FPC.0b013e3282f60db0

[26] Baumgartner, K.B., Schlierf, T.J., Yang, D., et al. (2009) $\mathrm{N}$-acetyltransferase 2 genotype modification of active cigarette smoking on breast cancer risk among hispanic and non-hispanic white women. The Journal of Toxicological Sciences, 112, 211-220. doi:10.1093/toxsci/kfp199

[27] Lin, H.J., Han, C.Y., Lin, B.K., et al. (1994) Ethnic distribution of slow acetylator mutations in the polymerphic N-acetyltransferase (NAT2) gene. Pharmacogenetics, 4, 125-134. doi:10.1097/00008571-199406000-00003

[28] Patin, E., Barreiro, L.B., Sabeti, P.C., et al. (2006) Deciphering the ancient and complex evolutionary history of human arylamine $\mathrm{N}$-acetyltransferase genes. The American Journal of Human Genetics, 78, 423-436. doi:10.1086/500614

[29] Gajecka, M., Rydzanicz, M., Jaskula-Sztul, R., et al. (2005) CYP1A1, CYP2D6, CYP2E1, NAT2, GSTM1 and 
GSTT1 polymorphisms or their combinations are associated with the increased risk of the laryngeal squa- mous cell carcinoma. Mutation Research, 574, 112-123. doi:10.1016/j.mrfmmm.2005.01.027

[30] Okkels, H., Sigsgaard, T., Wolf, H., et al. (1997) Arylamine $\mathrm{N}$-acetyltransferase 1 (NAT1) and 2 (NAT2) polymorphisms in susceptibility to bladder cancer: The influence of smoking. Cancer Epidemiology, Biomarkers \& Prevention, 6, 225-231.

[31] Bell, D.A., Taylor, J.A., Butler, M.A., et al. (1993) Short communication: Genotype/phenotype discordance for human arylamine $\mathrm{N}$-acetyltransferase (NAT2) reveals a new slow-acetylator allele common in African-americans. Carcinogenesis, 14, 1689-1692. doi:10.1093/carcin/14.8.1689

[32] Butler, L.M., Millikan, R.C., Sinha, R., et al. (2008) Modification by $\mathrm{N}$-acetyltransferase 1 genotype on the association between dietary heterocyclic amines and colon cancer in a multiethnic study. Mutation Research, 638, 162174. doi:10.1016/j.mrfmmm.2007.10.002

[33] Berg, N.D., Rasmussen, H.B., Linneberg, A., et al. (2010) Genetic susceptibility factors for multiple chemical sensitivity revisited. International Journal of Hygiene and Environmental Health, 213, 131-139. doi:10.1016/j.ijheh.2010.02.001

[34] Cascorbi, I., Drakoulis, N., Brockmoller, J., et al. (1995) Arylamine $\mathrm{N}$-acetylation (NAT2) mutations and their allelic linkage in unrelated caucasian individuals: Correlation with phenotypic activity. The American Journal of Human Genetics, 57, 581-592.

[35] Agundez, J.A., Olivera, M., Martinez, C., et al. (1996) Identification and prevalence study of 17 allelic variants of the human NAT2 gene in a white population. Pharmacogenetics, 6, 423-428. doi:10.1097/00008571-199610000-00006

[36] Lemos, M.C. and Regaterio, F.J. (1998) N-acetyltransferase genotypes in the Portuguese population. Pharmacogenetics, 8, 561-564. doi:10.1097/00008571-199812000-00013

[37] Johnson, N., Bell, P., Jonovska, V., et al. (2004) NAT gene polymorphisms and susceptibility to Alzheimer's disease: Identification of a novel NAT1 allelic variant. BMC Medical Genetics, 5, 6-14. doi:10.1186/1471-2350-5-6

[38] Smith, C.A., Wadelius, M., Gough, A.C., et al. (1997) A simplified assay for the arylamine $\mathrm{N}$-acetyltransferase 2 polymorphism validated by phenotyping with izonoazid. Journal of Medical Genetics, 34, 758-760. doi:10.1097/00008571-199702000-00010

[39] SNP500Cancer Database. http://snp500cancer.nci.nih.gov/home.cfm

[40] Lee, S.Y., Lee, K.A., Ki, C.S., et al. (2002) Complete sequencing of a genetic polymorphism in NAT2 in the Korean population. Clinical Chemistry, 48, 775-777.

[41] Dai, Y., Leng, S., Li, L., et al. (2009) Effects of genetic polymorphisms of $\mathrm{N}$-acetyltransferase on trichloroethyleneinduced hypersensitivity dermatitis among exposed workers. Industrial Health, 47, 479-486. doi:10.2486/indhealth.47.479

[42] Xie, H.G., Xu, Z.H., Yang, D.S., et al. (1997) Metaanalysis of phenotype and genotype of NAT2 deficiency in Chinese populations. Pharmacogenetics, 7, 503-514. doi:10.1097/00008571-199712000-00009

[43] Sekine, A., Saito, S., Lida, A., et al. (2001) Identification of single-nucleotide polymorphisms (SNPs) of human Nacetyltransferase genes NAT1, NAT2, AANAT, ARD1 and L1CAM in the Japanese population. Journal of $\mathrm{Hu}$ man Genetics, 46, 314-319. doi:10.1007/s100380170065

[44] Kukongviriyapan, V., Prawan, A., Tassaneyakul, W., et al. (2003) Arylamine N-acetyltransferase-2 genotypes in the Thai population. British Journal of Clinical Pharmacology, 55, 278-281. doi:10.1046/j.1365-2125.2003.01766.x

[45] Rouissi, K., Ouerhani, S., Marrakchi, R., et al. (2009) Combined effect of smoking and inherited polymorphisms in arylamine $\mathrm{N}$-acetyltransferase 2, glutathione S-transferases M1 and T1 on bladder cancer in a Tunisian population. Cancer Genetics and Cytogenetics, 190, 101-107. doi:10.1016/j.cancergencyto.2009.01.007

[46] Bakayev, V.V., Mohammadi, F., Bahadori, M., et al. (2004) Arylamine N-acetyltransferase 2 slow acetylator polymorphisms in unrelated Iranian individuals. European Journal of Clinical Pharmacology, 60, 467-471. doi:10.1007/s00228-004-0799-z

[47] Magalon, H., Patin, E., Austerlitz, F., et al. (2008) Population genetic diversity of the NAT2 gene supports a role of acetylation in human adaptation to farming in Central Asia. European Journal of Human Genetics, 16, 243-251. doi:10.1038/sj.ejhg.5201963

[48] Torkaman-Boutorabi, A., Hoormand, M., Naghdi, N., et al. (2007) Genotype and allele frequencies of N-acetyltransferase 2 and glutathione S-transferase in the Iranian population. Clinical and Experimental Pharmacology and Physiology, 34, 1207-1211. doi:10.1111/j.1440-1681.2007.04753.x

[49] Aynacioglu, A.S., Cascorbi, I., Mrozikiewicz, P.M., et al. (1997) Arylamine Nacetyltransferase (NAT2) genotypes in Turkish population. Pharmacogenetics, 7, 327-231. doi:10.1097/00008571-199708000-00008

[50] Hamdy, S.I., Hiratsuka, M., Narahara, K., et al. (2003) Genotype and allele frequencies of TPMT, NAT2, GST, SULT1A1 and MDR-1 in the Egyptian population. British Journal of Clinical Pharmacology, 55, 560-569. doi:10.1046/j.1365-2125.2003.01786.x

[51] Woolhouse, N.M., Qureshi, M.M., Bastaki, S.M., et al. (1997) Polymorphic N-acetyltransferase (NAT2) genotypeing of Emiratis. Pharmacogenetics, 7, 73-82. doi:10.1097/00008571-199702000-00010

[52] Delomenie, C., Sica, L., Grant, D.M., et al. (1996) Genotyping of the polymorphic N-acetyltransferase (NAT2*) gene locus in two native African populations. Pharmacogenetics, 6, 177-185. doi:10.1097/00008571-199604000-00004

[53] Sabbagh, A., Langaney, A., Darlu, P., et al. (2008) Worldwide distribution of $N A T 2$ diversity: Implications for NAT2 evolutionary history. BMC Medical Genetics, 9, 114. doi:10.1186/1471-2156-9-21

[54] Jorge-Nebert, L.F., Eichelbaum, M., Griese, E.U., et al. 
(2002) Analysis of six SNPs of NAT2 in Ngawbe and Embera amerindians of Panama and determination of the Embera acetylation phenotype using caffeine. Pharmacogenetics, 12, 39-48. doi:10.1097/00008571-200201000-00006

[55] Fuselli, S., Gilman, R.H., Chanock, S.J., et al. (2007) Analysis of nucleotide diversity of NAT2 coding region reveals homogeneity across native American populations and high intra-population diversity. The Pharmacogenomics Journal, 7, 144-152. doi:10.1038/sj.tpj.6500407

[56] Teixeira, R.L., Miranda, A.B., Pacheco, A.G., et al. (2007) Genetic profile of the arylamine N-acetyltransferase 2 coding gene among individuals from two different regions of Brazil. Mutation Research, 624, 31-40. doi:10.1016/j.mrfmmm.2007.03.015

[57] Talbot, J., Magno, L.A.V., Santana, C.V.N., Sousa, S.M.B., Melo, P.R.S., Correa, R.X., Di Pietro, G. and Rios-Santos, F. (2010) Interethnic diversity of NAT2 polymorphisms in Brazilian admixed populations. BMC Genetics, 11, 87-96. doi:10.1186/1471-2156-11-87

[58] Garcia-Martin, E. (2008) Interethnic and intraethnic variability of NAT2 single nucleotide polymorphisms. Current Drug Metabolism, 9, 487-497. doi:10.2174/138920008784892155

[59] Turesky, R.J., Bendaly, J., Yasa, I., et al. (2009) The acetilation de NAT2 genótipo sobre Mutagênese e adutos de DNA a partir de 2-amino-9H-pirido [2,3-b] indol. Chemical Research in Toxicology, 22, 726-733. doi:10.1021/tx800473w

[60] Di Pietro, G., Magno, L.A.M. and Rios-Santos, F. (2010) Glutathione S-transferases: An overview in cancer research. Expert Opinion on Drug Metabolism \& Toxicologyl, 6, 153-70. doi: $10.1517 / 17425250903427980$

[61] Vineis, P., Marinelli, D., Autrup, H., et al. (2001) Current smoking, occupation, $N$-acetyltransferase- 2 and bladder cancer; a pooled analysis of genotype-based studies. Cancer Epidemiology, Biomarkers \& Prevention, 10, 12491252.

[62] Jaskuła-Sztul, R., Sokołowski, W., Gajecka, M., et al. (2001) Association of arylamine N-acetyltransferase (NAT1 and NAT2) genotypes with urinary bladder cancer risk. Journal of Applied Genetics, 42, 223-231.

[63] Giannakopoulos, X., Charalabopoulos, K., Baltogiannis, D., et al. (2002) The role of $\mathrm{N}$-acetyltransferase-2 and glutathione S-transferase on the risk and aggressiveness of bladder cancer. Anticancer Research, 22, 3801-3804.

[64] Schroeder, J.C., Conway, K., Li, Y., et al. (2003) P53 mutations in bladder cancer: Evidence for exogenous versus endogenous risk factors. Cancer Research, 63, 75307538.

[65] García-Closas, M., Malats, N., Silverman, D., et al. (2005) NAT2 slow acetylation, GSTM1 null genotype, and risk of bladder cancer: results from the Spanish Bladder Cancer Study and meta-analyses. Lancet, 366, 649-59. doi:10.1016/S0140-6736(05)67137-1

[66] Gu, J., Liang, D., Wang, Y., et al. (2005) Effects of Nacetyltransferase 1 and 2 polymorphisms on bladder cancer risk in caucasians. Mutation Research, 581, 97-104. doi:10.1016/j.mrgentox.2004.11.012
[67] Dong, L.M., Potter, J.D., White, E., et al. (2008) Genetic susceptibility to cancer: The role of polymorphisms in candidate genes. JAMA, 299, 2423-2436. doi:10.1001/jama.299.20.2423

[68] Song, D.K., Xing, D.L., Zhang, L.R., et al. (2009) Association of NAT2, GSTM1, GSTT1, CYP2A6, and CYP2A13 gene polymorphisms with susceptibility and clinicopathologic characteristics of bladder cancer in Central China. Cancer Detection and Prevention Journal, 32, 416-423. doi:10.1016/j.cdp.2009.02.003

[69] Klimčáková, L., Habalová, V., Sivoňová, M., et al. (2010) Effect of NAT2 gene polymorphism on bladder cancer risk in Slovak population. Molecular Biology Reports, $\mathbf{3 8}$, 1287-1293

[70] García-Closas, M., Hein, D.W., Silverman, D., et al. (2011) A single nucleotide polymorphism tags variation in the arylamine $\mathrm{N}$-acetyltransferase 2 phenotype in populations of European background. Pharmacogenet Genomics, 21, 231-236.

[71] Frazier, M.L., O’Donnell, F.T., Kong, S., et al. (2001) bAgeassociated risk of cancer among individuals with $\mathrm{N}$-acetyltransferase 2 (NAT2) mutations and mutations in DNA mismatch repair genes. Cancer Research, 61, 12691271.

[72] Shibuta, J., Eto, T., Kataoka, A., et al. (2001) Genetic polymorphism of N-acetyltransferase 2 in patients with esophageal cancer. The American Journal of Gastroenterology, 96, 3419-3424. doi:10.1111/j.1572-0241.2001.05276.x

[73] Hahn, M., Hagedorn, G., Kuhlisch, E., et al. (2002) Genetic polymorphisms of drug-metabolizing enzymes and susceptibility to oral cavity cancer. Oral Oncology, 38, 486-490. doi:10.1016/S1368-8375(01)00086-0

[74] Varzim, G., Monteiro, E., Silva, R., et al. (2002) Polymorphisms of arylamine $\mathrm{N}$-acetyltransferase (NAT1 and NAT2) and larynx cancer susceptibility. ORL, 64, 206-212. doi:10.1159/000058026

[75] Unal, M., Tamer, L., Akbaş, Y., et al. (2005) Genetic polymorphism of $\mathrm{N}$-acetyltransferase 2 in the susceptibility to laryngeal squamous cell carcinoma. Head Neck, 27, 10561060. doi: $10.1002 /$ hed.20284

[76] Jain, M., Kumar, S., Lal, P., et al. (2007) Association of genetic polymorphisms of N-acetyltransferase 2 and susceptibility to esophageal cancer in north Indian population. Cancer Investigation, 25, 340-346. doi: 10.1080/07357900701358074

[77] Boccia, S., Cadoni, G., Sayed-Tabatabaei, F.A., et al. (2008) CYP1A1, CYP2E1, GSTM1, GSTT1, EPHX1 exons 3 and 4, and NAT2 polymorphisms, smoking, consumption of alcohol and fruit and vegetables and risk of head and neck cancer. Journal of Cancer Research and Clinical Oncology, 134, 93-100. doi:10.1007/s00432-007-0254-5

[78] Malik, M.A., Upadhyay, R., Modi, D.R., et al. (2009) Association of NAT2 gene polymorphisms with susceptibility to esophageal and gastric cancers in the Kashmir Valley. Archives of Medical Research, 40, 416-423. doi:10.1016/i.arcmed.2009.06.009 
[79] Boccia, S., Sayed-Tabatabaei, F.A., Persiani, R., et al. (2007) Polymorphisms in metabolic genes, their combination and interaction with tobacco smoke and alcohol consumption and risk of gastric cancer: A case-control study in an Italian population. BMC Cancer, 7, 206-214. doi:10.1186/1471-2407-7-206

[80] Zupa, A., Sgambato, A., Bianchino, G., et al. (2009) GSTM1 and NAT2 polymorphisms and colon, lung and bladder cancer risk: A case-control study. Anticancer Research, 29, 1709-1714.

[81] Wikman, H., Thiel, S., Jäger, B., et al. (2001) Relevance of N-acetyltransferase 1 and 2 (NAT1,NAT2) genetic polymorphisms in non-small cell lung cancer susceptibility. Pharmacogenetics, 11, 157-168. doi:10.1097/00008571-200103000-00006

[82] Hou, S.M., Fält, S., Yang, K., et al. (2001) Differential interactions between GSTM1 and NAT2 genotypes on aromatic DNA adduct level and HPRT mutant frequency in lung cancer patients and population controls. Cancer Epidemiology, Biomarkers \& Prevention, 10, 133-140.

[83] Habalová, V., Salagovic, J., Kalina, I., et al. (2005) A pilot study testing the genetic polymorphism of N-acetyltransferase 2 as a risk factor in lung cancer. Neoplasma, 52, 364-368.

[84] Osawa, Y., Osawa, K.K., Miyaishi, A., et al. (2007) NAT2 and CYP1A2 polymorphisms and lung cancer risk in relation to smoking status. Asian Pacific Journal of Cancer Prevention, 8, 103-108.

[85] Sobti, R.C., Kaur, P., Kaur, S., et al. (2009) Impact of interaction of polymorphic forms of p53 codon 72 and $\mathrm{N}$-acetylation gene (NAT2) on the risk of lung cancer in the North Indian population. DNA and Cell Biology, 28, 443- 449. doi:10.1089/dna.2008.0797

[86] Lee, M.S., Su, L. and Christiani, D.C. (2010) Synergistic effects of NAT2 slow and GSTM1 null genotypes on carcinogen DNA damage in the lung. Cancer Epidemiology, Biomarkers \& Prevention, 19, 1492-1497. doi:10.1158/1055-9965.EPI-09-1195

[87] Firozi, P.F., Bondy, M.L., Sahin, A.A., et al. (2002) Aromatic DNA adducts and polymorphisms of CYP1A1, NAT2, and GSTM1 in breast cancer. Carcinogenesis, 23, 301-306. doi:10.1093/carcin/23.2.301

[88] Egan, K.M., Newcomb, P.A., Titus-Ernstoff, L., et al. (2003) Association of NAT2 and smoking in relation to breast cancer incidence in a population-based case-control study (United States). Cancer Causes Control, 14, 4351. doi:10.1023/A:1022517506689

[89] Alberg, A.J., Daudt, A., Huang, H.Y., et al. (2004) N-acetyltransferase 2 (NAT2) genotypes, cigarette smoking, and the risk of breast cancer. Cancer Epidemiology, Biomarkers \& Prevention, 28, 187-193. doi:10.1016/j.cdp.2004.04.001

[90] Sillanpää, P., Hirvonen, A., Kataja, V., et al. (2005) NAT2 slow acetylator genotype as an important modifier of breast cancer risk. International Journal of Cancer, 114, 579584. doi:10.1002/ijc. 20677

[91] Khedhaier, A., Hassen, E., Bouaouina, N., et al. (2008) Implication of xenobiotic metabolizing enzyme gene (CYP2E1, CYP2C19, CYP2D6, mEH and NAT2) poly- morphisms in breast carcinoma. BMC Cancer, 8, 109. doi:10.1186/1471-2407-8-109

[92] Zhang, J., Qiu, L.X., Wang, Z.H., et al. (2010) NAT2 polymorphisms combining with smoking associated with breast cancer susceptibility: A meta-analysis. Breast Cancer Research and Treatment, 123, 877-883. doi:10.1007/s10549-010-0807-1

[93] Hein, D.W., Leff, M.A., Ishibe, N., et al. (2002) Association of prostate cancer with rapid $\mathrm{N}$-acetyltransferase 1 $\left(N A T 1^{*} 10\right)$ in combination with slow $\mathrm{N}$-acetyltransferase 2 acetylator genotypes in a pilot case-control study. Environmental and Molecular Mutagenesis, 40, 161-167. doi:10.1002/em.10103

[94] Hamasaki, T., Inatomi, H., Katoh, T., et al. (2003) N-acetyltransferase-2 gene polymorphism as a possible biomarker for prostate cancer in Japanese men. International Journal of Urology, 10, 167-173. doi:10.1046/j.1442-2042.2003.00586.x

[95] Gong, C., Hu, X., Gao, Y., et al. (2010) A meta-analysis of the NAT1 and NAT2 polymorphisms and prostate cancer: A huge review. Medical Oncology, 28, 365-367.

[96] Matullo, G., Guarrera, S., Carturan, S., et al. (2001) DNA repair gene polymorphisms, bulky DNA adducts in white blood cells and bladder cancer: In a case-control study. International Journal of Cancer, 92, 62-67. doi:10.1002/ijc. 1228

[97] Golka, K., Weistenhofer, W., Jedrusik, P., et al. (2001) $\mathrm{N}$-acetyltransferase 2 phenotype in painters with bladder cancer and controls. Annals Academy of Medicine Singapore, 30, 464- 467.

[98] Cascorbi, I., Roots, I. and Brockmöller, J. (2001) Association of NAT1 and NAT2 polymorphisms to urinary bladder cancer: significantly reduced risk in subjects with $N A T 1^{*} 10$. Cancer Research, 61, 5051-5056.

[99] Hung, R.J., Boffetta, P., Brennan, P., et al. (2004) GST, NAT, SULT1A1, CYP1B1 genetic polymorphisms, interactions with environmental exposures and bladder cancer risk in a high-risk population. International Journal of Cancer, 110, 598-604. doi:10.1002/ijc.20157

[100] Kellen, E., Zeegers, M., Paulussen, A., et al. (2007) Does occupational exposure to PAHs, diesel and aromatic amines interact with smoking and metabolic genetic polymorphisms to increase the risk on bladder cancer? The Belgian case control study on bladder cancer risk. Cancer Letters, 245, 51-60. doi:10.1016/j.canlet.2005.12.025

[101] Sanderson, S., Salanti, G. and Higgins, J. (2007) Joint effects of the $\mathrm{N}$-acetyltransferase 1 and 2 (NAT1 and $N A T 2$ ) genes and smoking on bladder carcinogenesis: A literature-based systematic HuGE review and evidence synthesis. American Journal of Epidemiology, 166, 741751. doi:10.1093/aje/kwm167

[102] Yuan, J.M., Chan, K.K., Coetzee, G.A., et al. (2008) Genetic determinants in the metabolism of bladder carcinogens in relation to risk of bladder cancer. Carcinogenesis, 29, 1386-1393. doi:10.1093/carcin/bgn136

[103] Fontana, L., Delort, L., Joumard, L., et al. (2009) Genetic polymorphisms in CYP1A1, CYP1B1, COMT, GSTP1 and $N A T 2$ genes and association with bladder cancer risk 
in a French cohort. Anticancer Research, 29, 1631-1635.

[104] Tao, L., Xiang, Y.B., Wang, R., et al. (2010) Environmental Tobacco Smoke in Relation to Bladder Cancer Risk-The Shanghai Bladder Cancer Study. Cancer Epidemiology, Biomarkers \& Prevention, 19, 3087-3095. doi:10.1158/1055-9965.EPI-10-0823

[105] Moore, L.E., Baris, D.R., Figueroa, J.D., et al. (2010) GSTM1 null and NAT2 slow acetylation genotypes, smoking intensity and bladder cancer risk: results from the New England bladder cancer study and NAT2 meta-analysis. Carcinogenesis, 32, 182-189. doi:10.1093/carcin/bgq223

[106] Nöthlings, U., Yamamoto, J.F., Wilkens, L.R., et al. (2009) Meat and heterocyclic amine intake, smoking, NAT1 and $N A T 2$ polymorphisms, and colorectal cancer risk in the multiethnic cohort study. Cancer Epidemiology, Biomarkers \& Prevention, 18, 2098-2106. doi:10.1158/1055-9965.EPI-08-1218

[107] Cotterchio, M., Boucher, B.A., Manno, M., et al. (2008) Red meat intake, doneness, polymorphisms in genes that encode carcinogen-metabolizing enzymes, and colorectal cancer risk. Cancer Epidemiology, Biomarkers \& Prevention, 17, 3098-3107. doi:10.1158/1055-9965.EPI-08-0341

[108] Tiemersma, E.W., Voskuil, D.W., Bunschoten, A., et al. (2004) Risk of colorectal adenomas in relation to meat consumption, meat preparation, and genetic susceptibility in a Dutch population. Cancer Causes Control, 15, 225236. doi:10.1023/B:CACO.0000024263.44973.92

[109] Cleary, S.P., Cotterchio, M., Shi, E., et al. (2010) Cigarette smoking, genetic variants in carcinogen-metabolizing enzymes, and colorectal cancer risk. American Journal of Epidemiology, 172, 1003-1014. doi:10.1093/aje/kwq245

[110] Silva, T.D., Felipe, A.V., Lima, J.M., Forones, N.M., et al. (2011) N-Acetyltransferase 2 genetic polymorphisms and risk of colorectal cancer. World Journal of Gastroenterology, 17, 760-765. doi:10.3748/wjg.v17.i6.760

[111] Zhang, Y.W., Eom, S.Y., Kim, Y.D., et al. (2009) Effects of dietary factors and the NAT2 acetylator status on gastric cancer in Koreans. International Journal of Cancer, 125, 139-145. doi:10.1002/ijc.24328

[112] Krajinovic, M., Ghadirian, P., Richer, C., et al. (2001) Genetic susceptibility to breast cancer in French-Canadians: Role of carcinogen-metabolizing enzymes and gene-environment interactions. International Journal of Cancer, 92, 220-225.

doi:10.1002/1097-0215(200102)9999:9999<::AID-IJC11 84>3.0.CO;2-H

[113] Chang-Claude, J., Kropp, S., Jäger, B., et al. (2002) Differential effect of NAT2 on the association between active and passive smoke exposure and breast cancer risk. Cancer Epidemiology, Biomarkers \& Prevention, 11, 698- 704.

[114] Conlon, M.S., Johnson, K.C., Bewick, M.A., et al. (2010) Smoking (active and passive), $\mathrm{N}$-acetyltransferase 2, and risk of breast cancer. Cancer Epidemiology, 34, 142-149. doi:10.1016/j.canep.2010.02.001

[115] Stephenson, N., Beckmann, L. and Chang-Claude, J. (2010)
Carcinogen metabolism, cigarette smoking, and breast cancer risk: A Bayes model averaging approach. Epidemiologic Perspectives \& Innovations, 7, 1-9.

doi:10.1186/1742-5573-7-10

[116] Lu, C.M., Chung, M.C., Huang, C.H., et al. (2005) Interaction effect in bladder cancer between $\mathrm{N}$-acetyltransferase 2 genotype and alcohol drinking. Urologia Internationalis, 75, 360-364. doi: $10.1159 / 000089175$

[117] Covolo, L., Placidi, D., Gelatti, U., et al. (2008) Bladder cancer, GSTs, NAT1, NAT2, SULT1A1, XRCC1, XRCC3, XPD genetic polymorphisms and coffee consumption: A case-control study. European Journal of Epidemiology, 23, 355-362. doi:10.1007/s10654-008-9238-2

[118] Villanueva, C.M., Silverman, D.T., Murta-Nascimento, C., et al. (2009) Coffee consumption, genetic susceptibility and bladder cancer risk. Cancer Causes Control, 20, 121-127. doi:10.1007/s10552-008-9226-6

[119] Castelao, J.E., Yuan, J.M., Gago-Dominguez, M., et al. (2004) Carotenoids/vitamin C and smoking-related bladder cancer. International Journal of Cancer, 110, 417 423. doi:10.1002/ijc.20104

[120] Zhao, H., Lin, J., Grossman, H.B., et al. (2007) Dietary isothiocyanates, GSTM1, GSTT1, NAT2 polymorphisms and bladder cancer risk. International Journal of Cancer, 120, 2208-2213. doi:10.1002/ijc. 22549

[121] Lin, J., Kamat, A., Gu, J., et al. (2009) Dietary intake of vegetables and fruits and the modification effects of GSTM1 and NAT2 genotypes on bladder cancer risk. Cancer Epidemiology, Biomarkers \& Prevention, 18, 2090-2097. doi:10.1158/1055-9965.EPI-08-1174

[122] Kellen, E., Zeegers, M., Paulussen, A., et al. (2006) Fruit consumption reduces the effect of smoking on bladder cancer risk. The Belgian case control study on bladder cancer. International Journal of Cancer, 118, 2572-2578. doi:10.1002/ijc. 21714

[123] Kiss, I., Németh, A., Bogner, B., et al. (2004) Polymorphisms of glutathione-S-transferase and arylamine $\mathrm{N}$-acetyltransferase enzymes and susceptibility to colorectal cancer. Anticancer Research, 24, 3965-3970.

[124] Osian, G., Procopciuc, L. and Vlad, L. (2006) NAT2 gene polymorphism and sporadic colorectal cancer: prevalence, tumor stage and prognosis. A preliminary study in 70 patients. Journal of Gastrointestinal and Liver Diseases, 15, 347-353.

[125] Tamer, L., Ercan, B., Ates, N.A., et al., (2006) N-acetyltransferase 2 gene polymorphism in patients with colorectal carcinoma. Cell Biochemistry and Function, 24, 131-135. doi:10.1002/cbf.1191

[126] Yoshida, K., Osawa, K., Kasahara, M., et al. (2007) Association of CYP1A1, CYP1A2, GSTM1 and NAT2 gene polymorphisms with colorectal cancer and smoking. Asian Pacific Journal of Cancer Prevention, 8, 438-444.

[127] Huang, C.C., Chien, W.P., Wong, R.H., et al. (2009) NAT2 fast acetylator genotype and MGMT promoter methylation may contribute to gender difference in K-RAS mutation occurrence in Taiwanese colorectal cancer. Environmental and Molecular Mutagenesis, 50, 127-133. 
doi:10.1002/em.20444

[128] Ye, Z. and Parry, J.M. (2002) Meta-analysis of 20 casecontrol studies on the N-acetyltransferase 2 acetylation status and colorectal cancer risk. Medical Science Monitor, 8, 558-565.

[129] Le Marchand, L., Hankin, J.H., Wilkens, L.R., et al. (2001) Combined effects of well-done red meat, smoking, and rapid $\mathrm{N}$-acetyltransferase 2 and CYP1A2 phenotypes in increasing colorectal cancer risk. Cancer Epidemiology, Biomarkers \& Prevention, 10, 1259-1266.

[130] Slattery, M.L., Curtin, K., Ma, K., et al. (2002) GSTM-1 and NAT2 and genetic alterations in colon tumors. Cancer Causes Control, 13, 527-534. doi:10.1023/A:1016376016716

[131] Chan, A.T., Tranah, G.J., Giovannucci, E.L., et al. (2005) Prospective study of N-acetyltransferase- 2 genotypes, meat intake, smoking and risk of colorectal cancer. International Journal of Cancer, 115, 648-652. doi:10.1002/ijc. 20890

[132] Barrett, J.H., Smith, G., Waxman, R., et al. (2003) Investigation of interaction between $\mathrm{N}$-acetyltransferase 2 and heterocyclic amines as potential risk factors for colorectal cancer. Carcinogenesis, 24, 275-282. doi:10.1093/carcin/24.2.275

[133] Lilla, C., Verla-Tebit, E., Risch, A., et al. (2006) Effect of NAT1 and NAT2 genetic polymorphisms on colorectal cancer risk associated with exposure to tobacco smoke and meat consumption. Cancer Epidemiology, Biomarkers \& Prevention, 15, 99-107. doi:10.1158/1055-9965.EPI-05-0618

[134] Ognjanovic, S., Yamamoto, J., Maskarinec, G., et al. (2006) NAT2, meat consumption and colorectal cancer incidence: An ecological study among 27 countries. Cancer Causes Control, 17, 1175-1182. doi:10.1007/s10552-006-0061-3

[135] Goode, E.L., Potter, J.D., Bamlet, W.R., et al. (2007) Inherited variation in carcinogen-metabolizing enzymes and risk of colorectal polyps. Carcinogenesis, 28, 328341. doi:10.1093/carcin/bgl135

[136] Sørensen, M., Autrup, H., Olsen, A., et al. (2008) Prospective study of NAT1 and NAT2 polymorphisms, tobacco smoking and meat consumption and risk of colorectal cancer. Cancer Letters, 266, 186-193. doi:10.1016/j.canlet.2008.02.046

[137] Gajecka, M., Rydzanicz, M., Jaskula-Sztul, R., et al. (2005) CYP1A1, CYP2D6, CYP2E1, NAT2, GSTM1 and GSTT1 polymorphisms or their combinations are associated with the increased risk of the laryngeal squamous cell carcinoma. Mutation Research, 574, 112-123. doi:10.1016/j.mrfmmm.2005.01.027

[138] Marques, C.F.S., Koifman, S., Koifman, R.J., et al. (2006) Influence of CYP1A1, CYP2E1, GSTM3 and NAT2 genetic polymorphisms in oral cancer susceptibility: Results from a case-control study in Rio de Janeiro. Oral Oncology, 42, 632-637. doi:10.1016/j.oraloncology.2005.11.003

[139] Buch, S.C., Nazar-Stewart, V., Weissfeld, J.L., et al. (2008) Case-control study of oral and oropharyngeal cancer in whites and genetic variation in eight metabolic enzymes.
Head Neck, 30, 1139-1147. doi:10.1002/hed.20867

[140] Demokan, S., Suoglu, Y., Gözeler, M., et al. (2010) Nacetyltransferase 1 and 2 gene sequence variants and risk of head and neck cancer. Molecular Biology Reports, 37, 3217- 3226. doi:10.1007/s11033-009-9905-8

[141] Chatzimichalis, M., Xenellis, J., Tzagaroulakis, A., et al. (2010) GSTT1, GSTM1, GSTM3 and NAT2 polymorphisms in laryngeal squamous cell carcinoma in a Greek population. The Journal of Laryngology \& Otology, 124, 318-323. doi:10.1017/S002221510999154X

[142] Zhou, W., Liu, G., Thurston, S.W., et al. (2002) Genetic polymorphisms in $\mathrm{N}$-acetyltransferase- 2 and microsomal epoxide hydrolase, cumulative cigarette smoking, and lung cancer. Cancer Epidemiology, Biomarkers \& Prevention, 11, 15-21.

[143] Lee, C.N., Yu, M.C., Bai, K.J., et al. (2009) NAT2 fast acetylator genotypes are associated with an increased risk for lung cancer with wildtype epidermal growth factor receptors in Taiwan. Lung Cancer, 64, 9-12. doi:10.1016/j.lungcan.2008.07.001

[144] Mittal, R.D., Srivastava, D.S.L. and Mandhani, A. (2004) $N A T 2$ gene polymorphism in bladder cancer: A study from north India. International Brazilian Journal of Urology, 30, 279-288. doi:10.1590/S1677-55382004000400003

[145] Kontani, K., Kawakami, M., Nakajima, T., et al. (2001) Tobacco use and occupational exposure to carcinogens, but not $\mathrm{N}$-acetyltransferase 2 genotypes are major risk factors for bladder cancer in the Japanese. Urological Research, 29, 199-204. doi:10.1007/s002400100182

[146] Ma, Q.W., Lin, G.F., Chen, J.G., et al. (2004) Polymorphism of $\mathrm{N}$-acetyltransferase 2 (NAT2) gene polymerphism in Shanghai population: Occupational and nonoccupational bladder cancer patient groups. Biomedical and Environmental Sciences, 17, 291-298.

[147] McGrath, M., Michaud, D. and De Vivo, I. (2006) Polymorphisms in GSTT1, GSTM1, NAT1 and NAT2 genes and bladder cancer risk in men and women. BMC Cancer, 6, 239-247. doi:10.1186/1471-2407-6-239

[148] Ishibe, N., Sinha, R., Hein, D.W., et al. (2002) Genetic polymorphisms in heterocyclic amine metabolism and risk of colorectal adenomas. Pharmacogenetics, 12, 145 150. doi:10.1097/00008571-200203000-00008

[149] Sachse, C., Smith, G., Wilkie, M.J.V., et al. (2002) A pharmacogenetic study to investigate the role of dietary carcinogens in the etiology of colorectal cancer. Carcinogenesis, 23, 1839-1849. doi:10.1093/carcin/23.11.1839

[150] Prawan, A., Kukongviriyapan, V., Tassaneeyakul, W., et al. (2005) Association between genetic polymorphisms of CYP1A2, arylamine $\mathrm{N}$-acetyltransferase 1 and 2 and susceptibility to cholangiocarcinoma. European Journal of Cancer Prevention, 14, 245-250. doi:10.1097/00008469-200506000-00008

[151] Pistorius, S., Görgens, H., Krüger, S., et al. (2006) N-acetyltransferase $(N A T) 2$ acetylator status and age of onset in 
patients with hereditary nonpolyposis colorectal cancer (HNPCC). Cancer Letters, 241, 150-157.

doi:10.1016/j.canlet.2005.10.018

[152] Borlak, J. and Reamon-Buettner, S.M. (2006) N-acetyltransferase 2 (NAT2) gene polymorphisms in colon and lung cancer patients. BMC Medical Genetics, 7, 58-67. doi:10.1186/1471-2350-7-58

[153] Talseth, B.A., Meldrum, C., Suchy, J., et al. (2006) Genetic polymorphisms in xenobiotic clearance genes and their influence on disease expression in hereditary nonpolyposis colorectal cancer patients. Cancer Epidemiology, Biomarkers \& Prevention, 15, 2307-2310. doi:10.1158/1055-9965.EPI-06-0040

[154] Pistorius, S., Göergens, H., Engel, C., et al. (2007) N-acetyltransferase (NAT) 2 acetylator status and age of tumour onset in patients with sporadic and familial, microsatellite stable (MSS) colorectal cancer. International Journal of Colorectal Disease, 22, 137-143. doi:10.1007/s00384-006-0171-0

[155] Mahid, S.S., Colliver, D.W., Crawford, N.P., et al. (2007) Characterization of $\mathrm{N}$-acetyltransferase 1 and 2 polymorphisms and haplotype analysis for inflammatory bowel disease and sporadic colorectal carcinoma. $B M C$ Medical Genetics, 8, 28. doi:10.1186/1471-2350-8-28

[156] Raimondi, S., Botteri, E., Iodice, S., et al. (2009) Genesmoking interaction on colorectal adenoma and cancer risk: Review and meta-analysis. Mutation Research, 670, 6-14. doi:10.1016/j.mrfmmm.2009.06.013

[157] Liu, H., Fu, Z., Wang, C.Y., Qian, J., Xing, L. and Liu, Y.W. (2012) A Meta-analysis of the relationship between $N A T$ polymorphism and colorectal cancer susceptibility Medicina, 48, 117-131.

[158] Zhang, L.Q., Zhou, J.N., Wang, J., et al. (2012) Absence of association between n-acetyltransferase 2 acetylator status and colorectal cancer susceptibility: Based on evidence from 40 studies. PLoS ONE, 7, e32425. doi:10.1371/journal.pone.0032425

[159] Tiemersma, E.W., Kampman, E., Bueno de Mesquita, H.B., et al. (2002) Meat consumption, cigarette smoking, and genetic susceptibility in the etiology of colorectal cancer: results from a Dutch prospective study. Cancer Causes Control, 13, 383-393. doi:10.1023/A:1015236701054

[160] Moslehi, R., Chatterjee, N., Church, T.R., et al. (2006) Cigarette smoking, $\mathrm{N}$-acetyltransferase genes and the risk of advanced colorectal adenoma. Pharmacogenomics, 7, 819- 829. doi:10.2217/14622416.7.6.819

[161] Kobayashi, M., Otani, T., Iwasaki, M., et al. (2009) Association between dietary heterocyclic amine levels, genetic polymorphisms of NAT2, CYP1A1, and CYP1A2 and risk of colorectal cancer: A hospital-based case-control study in Japan. Scandinavian Journal of Gastroenterology, 44, 952-959. doi:10.1080/00365520902964721

[162] Kidd, L.C.R., Van Cleave, T.T., Doll, M.A., et al. (2011) No association between variant $N$-acetyltransferase genes, cigarette smoking and prostate cancer susceptibility among men of African descent. Biomark Cancer, 2011, $1-13$.
[163] Zheng, Y., Li, Y., Teng, Y., et al. (2012) Association of NAT2 phenotype with risk of head and neck carcinoma: A meta-analysis. Oncology Letters, 3, 429-434.

[164] Chen, C., Ricks, S., Doody, D.R., et al. (2001) N-acetyltransferase 2 polymorphisms, cigarette smoking and alcohol consumption, and oral squamous cell cancer risk. Carcinogenesis, 22, 1993-1999. doi:10.1093/carcin/22.12.1993

[165] Sørensen, M., Autrup, H., Tjønneland, A., et al. (2005) Genetic polymorphisms in CYP1B1, GSTA1, NQO1 and NAT2 and the risk of lung cancer. Cancer Letters, 221, 185-190. doi:10.1016/j.canlet.2004.11.012

[166] Belogubovaa, E.V., Kuliginaa, E.S., Togoa, A.V., et al. (2005) Comparison of extremes approach provides evidence against the modifying role of NAT2 polymorphism in lung cancer susceptibility. Cancer Letters, 221, 177183. doi:10.1016/j.canlet.2004.11.008

[167] Gemignani, F., Landi, S., Szeszenia-Dabrowska, N., et al. (2007) Development of lung cancer before the age of 50: The role of xenobiotic metabolizing genes. Carcinogenesis, 28, 1287-1293. doi:10.1093/carcin/bgm021

[168] Lee, K.M., Park SK, Kim SU, et al. (2003) N-acetyltransferase $(N A T 1, N A T 2)$ and glutathione S-transferase (GSTM1, GSTT1) polymorphisms in breast cancer. Cancer Letters, 196, 179-186. doi:10.1016/S0304-3835(03)00311-2

[169] Egeberg, R., Olsen, A., Autrup, H., et al. (2008) Meat consumption, $\mathrm{N}$-acetyl transferase 1 and 2 polymorphism and risk of breast cancer in Danish postmenopausal women. European Journal of Cancer Prevention, 17, 39-47. doi:10.1097/CEJ.0b013e32809b4cdd

[170] Kocabaş, N.A., Sardaş, S., Cholerton, S., et al. (2004) N-acetyltransferase (NAT2) polymorphism and breast cancer susceptibility: A lack of association in a case-control study of Turkish population. International Journal of Toxicology, 23, 25-31. doi:10.1080/10915810490275053

[171] van der Hel, O.L., Peeters, P.H., Hein, D.W., et al. (2004) GSTM1 null genotype, red meat consumption and breast cancer risk (The Netherlands). Cancer Causes Control, 15, 295-303. doi:10.1023/B:CACO.0000024255.16305.f4

[172] Lash, T.L., Bradbury, B.D., Wilk, J.B., et al. (2005) A case-only analysis of the interaction between $\mathrm{N}$-acetyltransferase 2 haplotypes and tobacco smoke in breast cancer etiology. Breast Cancer Research, 7, 385-393. doi:10.1186/bcr1013

[173] Lissowska, J., Brinton, L.A., Zatonski, W., et al. (2006) Tobacco smoking, NAT2 acetylation genotype and breast cancer risk. International Journal of Cancer, 119, 19611969. doi:10.1002/ijc.22044

[174] Ochs-Balcom, H.M., Wiesner, G. and Elston, R.C. (2007) A meta-analysis of the association of $\mathrm{N}$-acetyltransferase 2 gene (NAT2) variants with breast cancer. American Journal of Epidemiology, 166, 246-254. doi:10.1093/aje/kwm066

[175] Mignone, L.I., Giovannucci, E., Newcomb, P.A., et al. (2009) Meat consumption, heterocyclic amines, NAT2, and the risk of breast cancer. Nutrition and Cancer, 61, 


\section{6-46. doi:10.1080/01635580802348658}

[176] Taja-Chayeb, L., Agúndez, J.A., Miguez-Muñoz, C., et al. (2012) Arylamine N-acetyltransferase 2 genotypes in a Mexican population. Genetics and Molecular Research, 11, 1082-1092. doi:10.4238/2012.April.27.7

[177] Srivastava, D.S. and Mittal, R.D. (2005) Genetic polymorphism of the $\mathrm{N}$-acetyltransferase 2 gene, and susceptibility to prostate cancer: a pilot study in north Indian population. BMC Urology, 5, 12-18. doi:10.1186/1471-2490-5-12

[178] Rovito Jr., P.M., Morse, P.D., Spinek, K., et al. (2005) Heterocyclic amines and genotype of N-acetyltransferases as risk factors for prostate cancer. Prostate Cancer and Prostatic Diseases, 8, 69-74. doi:10.1038/sj.pcan. 4500780

[179] Costa, S., Pinto, D., Morais, A., et al. (2005) Acetylation genotype and the genetic susceptibility to prostate cancer in a southern European population. Prostate, 64, 246-252. doi:10.1002/pros.20241

[180] Sharma, S., Cao, X., Wilkens, L.R., et al. (2010) Welldone meat consumption, NAT1 and NAT2 acetylator genotypes and prostate cancer risk: the multiethnic cohort study. Cancer Epidemiology, Biomarkers \& Prevention, 19, 1866-1870. doi:10.1158/1055-9965.EPI-10-0231

[181] Zhong, X., Hui, C., Xiao-Ling, W., et al. (2010) NAT2 polymorphism and gastric cancer susceptibility: A metaanalysis. Archives of Medical Research, 41, 275-280. doi:10.1016/j.arcmed.2010.06.001

[182] Al-Moundhri, M.S., Al-Kindi, M., Al-Nabhani, M., et al. (2007) NAT2 polymorphism in Omani gastric cancer patients-risk predisposition and clinico pathological associations. World Journal of Gastroenterology, 13, 26972702.

[183] Kobayashi, M., Otani, T., Iwasaki, M., et al. (2009) As- sociation between dietary heterocyclic amine levels, genetic polymorphisms of NAT2, CYP1A1, and CYP1A2 and risk of stomach cancer: a hospital-based case-control study in Japan. Gastric Cancer, 12, 198-205. doi:10.1007/s10120-009-0523-X

[184] Bartsch, H., Nair, U., Risch, A., et al. (2000) Genetic polymorphism of CYP genes, alone or in combination, as a risk modifier of tobacco-related cancers. Cancer Epidemiology, Biomarkers \& Prevention, 9, 3-28.

[185] Zhang, X.F., Bian, J.C., Zhang, X.Y., et al. (2005) Are polymorphisms of $\mathrm{N}$-acetyltransferase genes susceptible to primary liver cancer in Luoyang, China? World Journal of Gastroenterology, 11, 1457-1462.

[186] Hein, D.W., Doll, M.A., Rustan, T.D., et al. (1995) Metabolic activation of N-hydroxyarylamines and N-hydroxyarylamides by 16 recombinant human NAT2 allozymes: effects of 7 specific NAT2 nucleic acid substitutions. Cancer Research, 55, 3531-3536.

[187] Hein, D.W., Fretland, A.J. and Doll, M.A. (2006) Effects of single nucleotide polymorphisms in human $\mathrm{N}$-acetyltransferase 2 on metabolic activation (O-acetylation) of heterocyclic amine carcinogens. International Journal of Cancer, 119, 1208-1211. doi:10.1002/ijc.21957

[188] Kawamura, A., Graham, J., Mushtaq, A., et al. (2005) Eukaryotic arylamine $\mathrm{N}$-acetyltransferase. Investigation of substrate specificity by high-throughput screening. Biochemical Pharmacology, 69, 347-359. doi:10.1016/j.bcp.2004.09.014

[189] Walraven, J.M., Trent, J.O. and Hein, D.W. (2007) Computational and experimental analyses of mammalian arylamine N-acetyltransferase structure and function. Drug Metabolism and Disposition, 35, 1001-1007. doi:10.1124/dmd.107.015040 